\title{
An Improved Experimental Test Set-up to Study the Performance of Granular Columns
}

\begin{abstract}
This paper describes an innovative design of a newly developed large test setup for testing the performance of footings supported on soft clay reinforced with granular columns. This advanced testing method is used to examine the settlement of footings supported on granular columns. Two important features of the equipment are (a) the axial loading system which allows samples to be consolidated under $\mathrm{K}_{0}$ condition while the load is applied onto a small foundation area of the sample, and (b) a relatively large sample size of 300-mm diameter and 400-mm high. The system is also equipped with pressure cells located beneath the footing and top cap to measure the pressure distribution with respect to foundation displacement and a lateral strain gage to monitor boundary effects. This paper reports on some of the early findings from the preliminary tests carried out using this equipment. Samples for testing were prepared by consolidating kaolin slurry in a large one-dimensional consolidation chamber. The granular columns were installed using the replacement method by compacting crushed basalt (uniformly graded with $90 \%$ between $1.5-2$-mm particle sizes) into a preformed hole. The preliminary tests have yielded promising results, validating the functionality of the equipment and support the prospect of increasing the knowledge with respect to settlement response and design of a footing supported on granular columns.
\end{abstract}

KEYWORDS: ground improvement, granular columns, settlement, stress path tests

\section{Introduction}

Infrastructure development is the key factor that determines the economical success of a nation. Such infrastructure developments are inevitably associated with civil works, in the form of highways, railways and buildings. In recent years emphasis has been on sustainable development (Serridge 2004). Sustainable development in the construction industry can be achieved in many ways including utilization of unsuitable land and reuse of construction byproducts or wastes (McKelvey 2002). In relation to the former, a significant number of engineering projects are now taking place on sites, which due to poor ground conditions would not previously have been considered economical to develop. Examples of these sites include soft deposits, derelict land, filled ground, and contaminated soils. Use of these sites for construction requires coherent and economical construction techniques. Ever-increasing costs compel the transition from conventional remedial works to more desirable methods of improving the ground performance in terms of cost effectiveness, durability, and sustainability. Various ground improvement methods are widely used by the construction industry to improve properties of weak in-situ materials. In this respect, techniques currently employed in practice include granular columns, preloading, grouting, admixtures, and thermal stabilization. Many of these procedures are well established; however, some still require further research in order to enhance their performance.

Granular columns are gaining acceptance within the construction industry, as they are applicable to a wide range of ground con-

Manuscript received June 17, 2005; accepted for publication January 24, 2006; published online February 2006.

${ }^{1}$ Research Student, School of Civil Engineering, Queen's University Belfast, Belfast United Kingdom.

${ }^{2}$ Senior Lecturer, School of Civil Engineering, Queen's University Belfast, Belfast United Kingdom.

${ }^{3}$ Professor Emeritus, Geoenvironmental Engineering Centre, J. N. Technical University, Hyderabad, India.

${ }^{4}$ Lecturer, Department of Civil Engineering, National University of Ireland, Galway. ditions and soil strengths. The granular column technique provides improved load bearing capacity and increased stiffness, and consequently, reduced settlements. Upon loading, granular columns develop end bearing and side frictional resistance in a similar fashion as piles. Granular columns also expand transversely and therefore acquire shear resistance from the surrounding soil (Fig. 1 Hughes and Withers 1974). The additional lateral stress due to column bulging enhances consolidation of the clay and further bulging of the column. Overall performance of the composite structure is controlled by the lateral support provided by the surrounding clay, which typically increases with depth. A better understanding of how granular columns contribute to the improved performance of soft clays in relation to bearing capacity and particularly settlement performance needs an improved testing protocol, which forms the basis of the paper.

In general, laboratory-based research has been invaluable to increase the understanding of granular columns. While many researchers may argue the relevance of $1 \mathrm{~g}$ laboratory model tests, it must be appreciated that for research and development purposes they are a cost effective and viable approach to preliminary investigation. Progress, in terms of laboratory, analytical, and full-scale

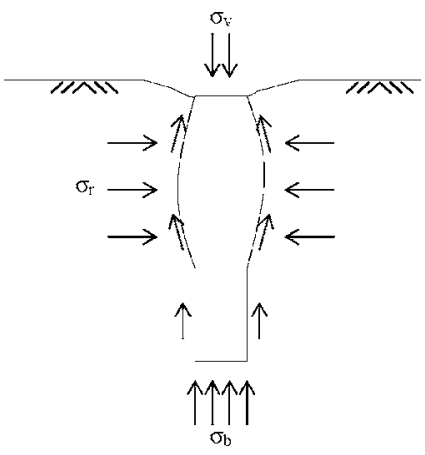

FIG. 1-Stresses during loading of a vibrated stone column (Hughes and Withers 1974). 
field work has been made for the estimation of load carrying capacity of granular columns; however, little information is available on the question of settlement of footings supported on granular columns. The limited research is primarily due to experimental difficulties experienced during sample preparation and foundation loading. Current laboratory testing considers samples that are simply consolidated one dimensionally. The difficulties experienced primarily relate to the frictional resistance between (a) clay and the consolidation chamber, and (b) loading piston and the loading chamber. The consequence of the boundary interaction is that the vertical pressure distribution in the clay bed is nonuniform which impinges on the homogeneity of the sample in relation to stiffness and strength. This also affects the lateral stresses in the clay significantly when the tests are performed in the one-dimensional consolidation chamber. Hughes and Withers (1974) and McKelvey (2004) recognized this as a potential problem for analyzing results because of complex stress systems involved. In addition, samples have been tested under undrained conditions on the assumption that short-term stability is more critical than the long-term stability in relation to bearing capacity considerations. Any analysis with respect to settlement predictions using these tests can be difficult for various reasons. Consideration of settlement will necessitate an "effective stress analysis." Controlling both total stress (foundation load and the surcharge) and pore water pressure in laboratory model testing is not easy, particularly when the clay bed is contained in a one-dimensional loading chamber. Controlling pore water pressure in a one-dimensional loading chamber would require a tight seal between the loading piston and the loading chamber. This will inevitably generate additional frictional resistance between the two components, and consequently, on the consolidation pressure applied on the sample (McKelvey 2002). These shortcomings often prevail not only in testing of granular columns, but also in other model studies in relation to piles and shallow foundations (Anderson et al. 1991). This paper describes an innovative testing setup and procedure to approach the above issue.

\section{Equipment and Validation Procedures}

\section{Dual Loading System}

As part of a research program to study the settlement characteristics and behavior of granular columns, it was necessary to design and construct equipment to overcome the experimental difficulties (Hughes and Withers 1974; McKelvey 2002) as indicated in the above paragraph. The challenge in the proposed research is to advance the technology to examine the settlement performance of footings supported on soft clay reinforced with granular columns (McKelvey et al. 2004). Particular significance of the equipment relies on its ability to test large samples consolidated under $\mathrm{K}_{\mathrm{o}}$ conditions while applying the foundation load independently. Figure 2 shows a schematic illustration of the proposed loading arrangement. The objective was to control both vertical and horizontal stresses acting on the sample to maintain $\mathrm{K}_{\mathrm{o}}$ condition during the consolidation process and then apply an independent foundation load via the footing that forms a part of the top cap placed at the top of the sample.

Figure 3 shows the newly developed dual loading triaxial system. The system is capable of testing $300-\mathrm{mm}$ diameter by 400-mm high samples. Although this increased sample size may not appear as a significant advancement to represent near full-scale

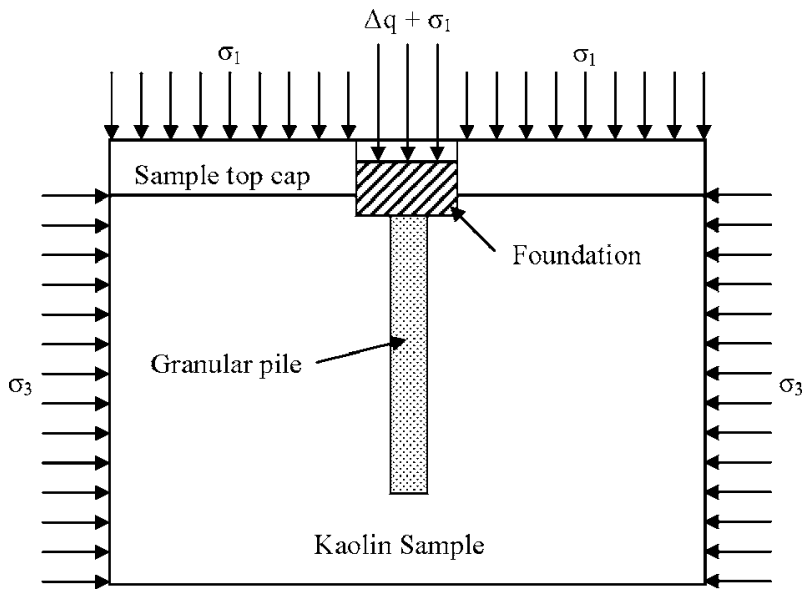

FIG. 2-Proposed loading configuration and test setup.

testing, it represents an overall volume increase of 18 times greater than a standard $100-\mathrm{mm}$ diameter and $200-\mathrm{mm}$ triaxial samples. A large triaxial cell was designed based on the configuration of the standard cell incorporating special features to meet the criteria of

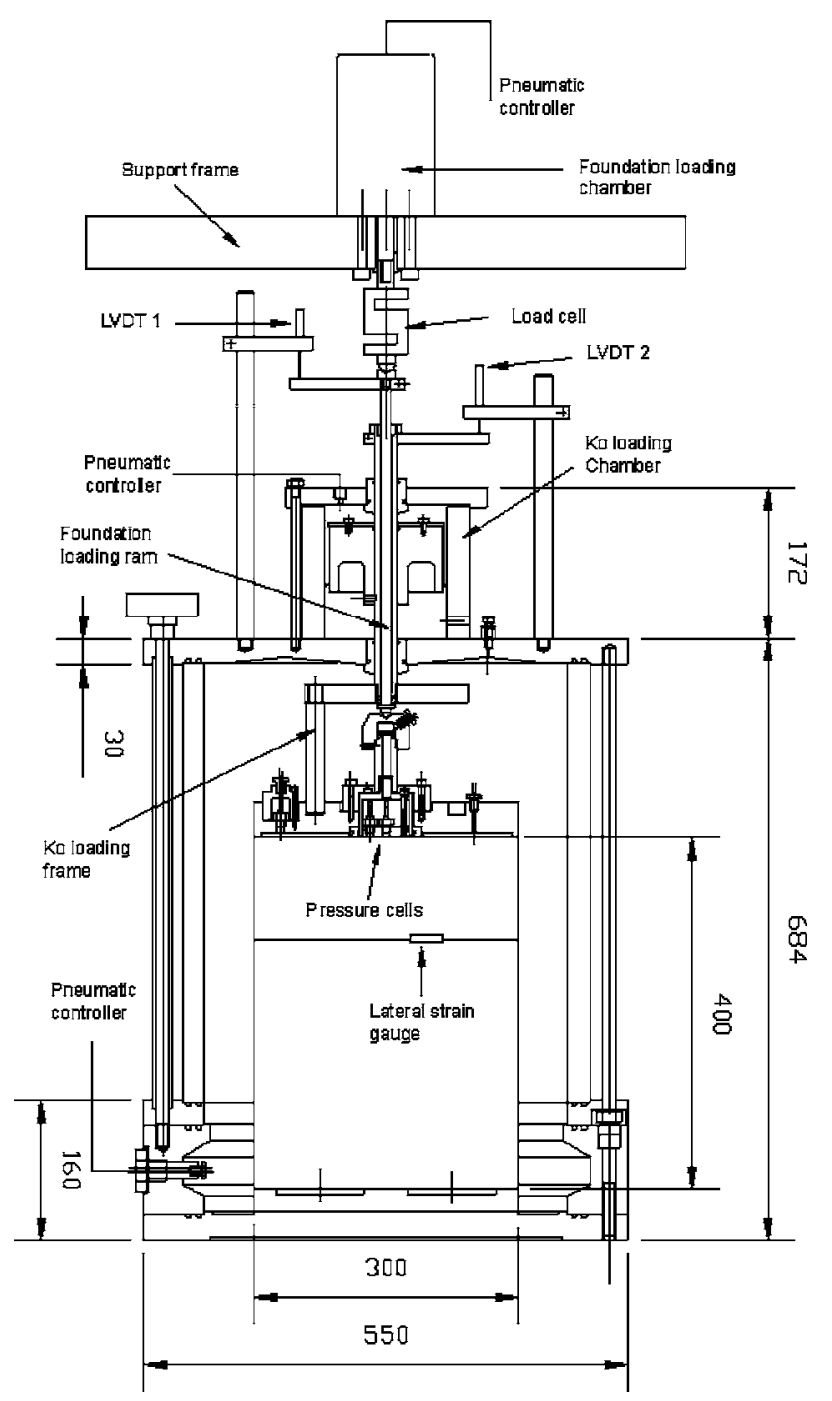

FIG. 3-Sectional view of the test setup (not to scale). 


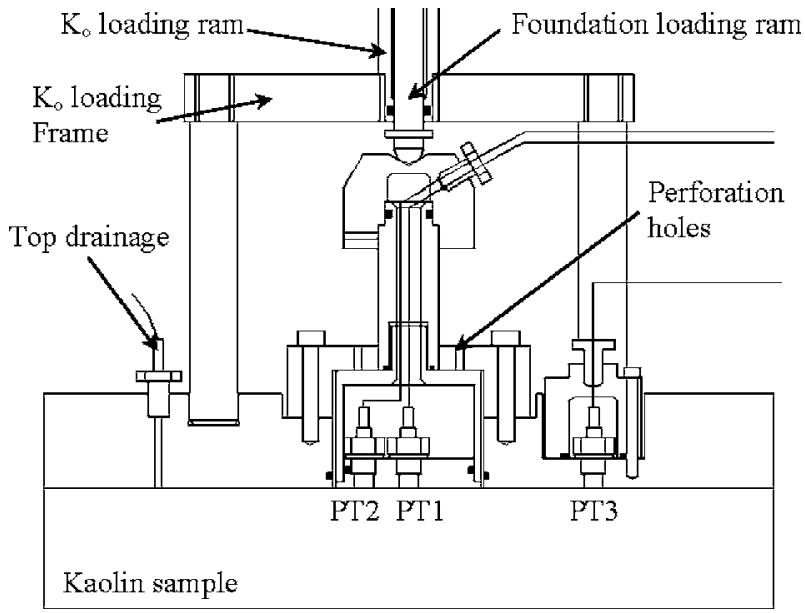

FIG. 4-Section showing top cap and foundation detail (not to scale).

testing soft clay samples reinforced with granular piles. The top and bottom plates of the large triaxial cell were manufactured from aluminum, $25-\mathrm{mm}$ thick and $550 \mathrm{~mm}$ in diameter. The bottom plate contains the usual terminals to connect cell pressure and drainage lines. An aluminum spacer ring attached to the base provides greater height within the cell and incorporates nine outlets for the various instrumentations required within the cell. The top plate integrates a dual loading system that is capable of applying a vertical stress onto the sample to achieve $\mathrm{K}_{\mathrm{o}}$ loading condition and apply an independent foundation loading on the reinforced clay bed via a 60 -mm diameter footing located within the top cap.

Additional details of this particular arrangement are shown in Fig. 4. The footing is housed and fastened to the top plate. The retaining cap is perforated with four small weep holes that allow cell pressure to act on the back of the footing during initial consolidation and $\mathrm{K}_{\mathrm{o}}$ loading. This ensures a uniform pressure distribution along the rigid top plate and prevents a vacuum being created when foundation load is applied. The design also incorporates features that will allow $\mathrm{K}_{\mathrm{o}}$ loading to be equally applied on the footing area. The footing is instrumented with two pressure cells, one located at the center of the footing and the other located closer to the footing boundary. A third pressure cell is located away from the footing and measures the vertical stress of the surrounding soil. The electrical cables are taken out of the footing using a special arrangement.

Application of cell pressure will subject the sample to isotropic compression. $\mathrm{K}_{\mathrm{o}}$ loading is achieved by controlling both vertical and horizontal pressures using pneumatic controllers. The lateral strain gage located at 1/3 sample height is used to ensure zero lateral strain during $\mathrm{K}_{\mathrm{o}}$ loading. Note here that the lateral strain gage will also examine the boundary effects of the granular columns during foundation loading. The authors accept that to ensure $\mathrm{K}_{\mathrm{o}}$ condition and to monitor full boundary conditions a lateral strain profile should be measured along the entire height of the sample. However, the critical location for lateral expansion is coupled with column budging which is known to be concentrated on the upper part of the granular column in the soft clay (Balaam 1978; Muir Wood et al. 2000). The $\mathrm{K}_{\mathrm{o}}$ loading system operates using the technique of a rolling diaphragm attached to a piston and a loading ram. The loading ram extends on both sides of the $K_{o}$ chamber. The ram that protrudes inside the large cell is attached to a three-legged plate that rests within a locating recess on the top cap placed on the sample.

Foundation load is applied by operating a pneumatic loading de-

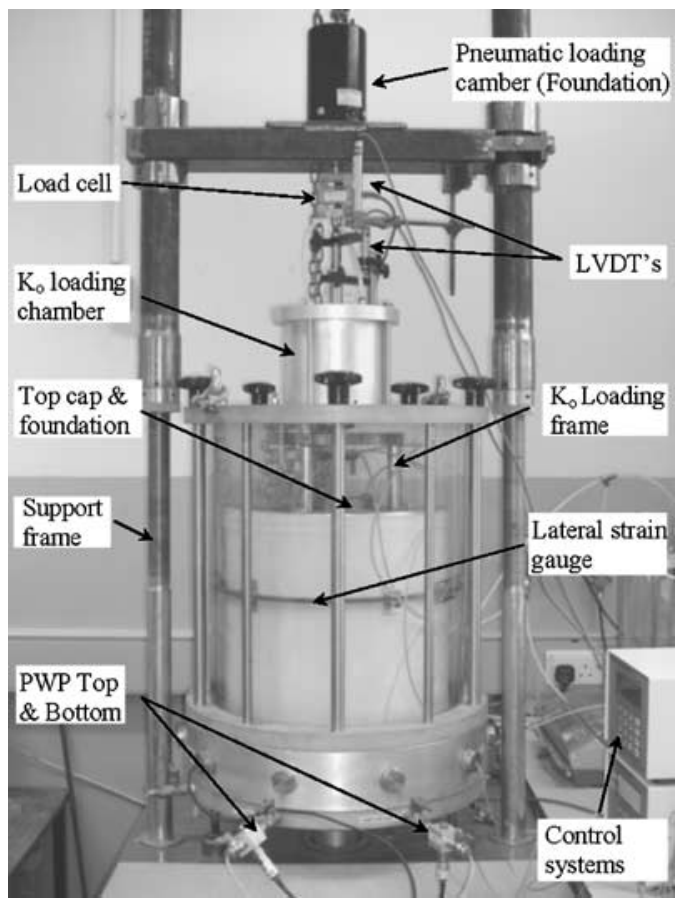

FIG. 5-Triaxial cell apparatus.

vice located at the supporting frame (Fig. 3). A thin slender loading ram is located inside the larger loading ram (designated for $\mathrm{K}_{\mathrm{o}}$ loading) that extends through the test chamber. This rod is supported on linear bearings, which reduces friction and ensures freefall under its own weight, though "O" rings are used to prevent leaks. A digital image of the entire system is shown in Fig. 5.

Samples are consolidated to required vertical and horizontal effective stresses. A 1-L volume change unit is used to measure the sample volume change during the consolidation, $\mathrm{K}_{\mathrm{o}}$, and foundation loadings. An additional feature incorporated in the system is the ability to generate a hydraulic gradient between the top and bottom of the sample and to allow the sample to attain a variable strength along the length. This will help model and represent to some extent the field condition where the strength of the soil increases with depth in normally consolidated clays.

The newly developed system is complex and has numerous devices that provide continuous monitoring of the sample throughout the duration of test. The devices include: five pressure traducers (10 bar range), three pressure cells (XPM10 range $0-20$ bar obtained from FGP sensors, France), calibrated two LVDTs $(5 \mathrm{~cm}$ and $2 \mathrm{~cm}$ stroke lengths), one internal strain gage $(5 \mathrm{~cm}$ travel distance), one differential pressure transducer (used in $1 \mathrm{~L}$ volume change unit), load cell ( $5 \mathrm{kN})$, and two pneumatic pressure controllers to apply $\mathrm{K}_{\mathrm{o}}$ and foundation loadings. These devices facilitate the loadings to be applied gradually in ramped fashion at a given rate. All these transducers are read by a 16 channel-data logger (MPX 3000) integrated with WinHOST V4.31. A special housing was made to calibrate the pressure cells used by Geotechnical Digital Device (GDS). The quality of the pressure measurements obtained using these pressure cells is good (Navaneethan 2003).

\section{Sampling Technique}

The research uses commercially available kaolin for making samples. Samples are prepared by consolidating $35 \mathrm{~kg}$ of kaolin 


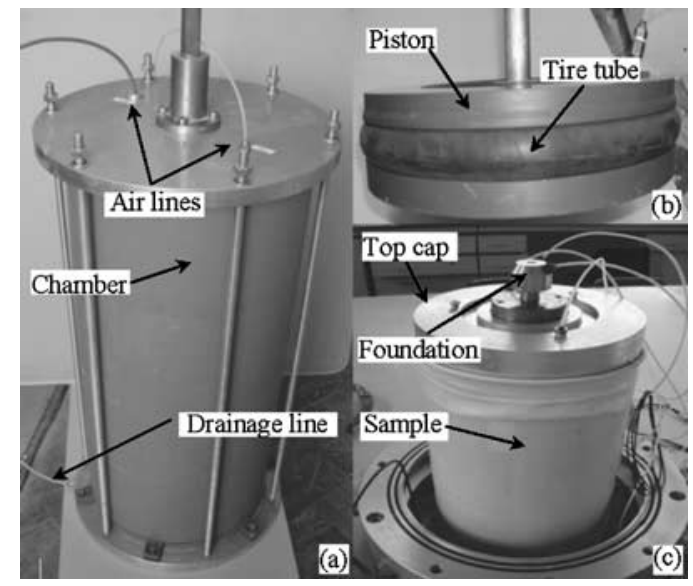

FIG. 6-Photographs of sample preparation (a) consolidation chamber, (b) piston incorporating rubber tube, and (c) completed sample for testing.

powder mixed at a water content of $105 \%$; that is approximately 1.5 times the liquid limit ( $\mathrm{LL}=70 \%$; Black 2003) in a onedimensional mold (Fig. 6(a)). Note here that the samples are prepared under rigid lateral boundary conditions. Sivakumar et al. (2002) reported a procedure to prepare samples from slurry state under flexible boundary conditions. However, this approach is too tedious to be considered in large size samples. Nevertheless, when the samples are reconsolidated in the large triaxial cell it is assumed that the stress levels that are used in the large triaxial cell are sufficiently high to eliminate any one-dimensional loading history that might have existed in the sample.

It is always a concern how to make quality large samples for testing. The standard approach used by many researchers is the arrangement where a rolling convoluted belloframe is attached to the piston. This particular technique works satisfactorily in short consolidation chambers; however, researchers have reported a number of difficulties while using this method in larger diameter chambers (Anderson et al. 1991; Navaneethan 2003; McKelvey 2002). An innovative method to produce large diameter triaxial samples is adopted in the present research. Given the large volume change that would occur during consolidation it was important to ensure that the chamber accommodates the initial volume of slurry required to produce a sample of $400 \mathrm{~mm}$ final height. The consolidation chamber was fabricated from a high performance polyethylene (HPPE) mains water pipe, (BS EN ISO 9002: 1994) internal diameter (ID) $295 \mathrm{~mm}$, outside diameter (OD) $360 \mathrm{~mm}$. The pipe was machined to leave an ID of $300 \mathrm{~mm}$, OD of $350 \mathrm{~mm}$ and height of $900 \mathrm{~mm}$. A wall thickness of $25 \mathrm{~mm}$ ensures the pipe has the capability of withstanding pressures of up to $800 \mathrm{kPa}$.

The top and bottom plates used to seal the chamber were manufactured from aluminum and have dimensions of 420-mm diameter by $25-\mathrm{mm}$ thick and are connected with six steel tie rods of $12-\mathrm{mm}$ diameter. The base plate allows for drainage and incorporates a 6-mm thick filter sheet with a diameter of $295 \mathrm{~mm}$ recessed flush with its surface. The top plate incorporates two air lines: one to apply consolidation pressure and the other to inflate the stabilizing bush. The piston rod is a $25-\mathrm{mm}$ diameter smooth brass rod and is connected to the piston plate. It is this piston plate that comprises a new innovative design to eliminate the problems associated with using a rolling belloframe.

This plate was manufactured from PVC and has dimensions of 298-mm diameter by 60-mm thickness. A "c" shaped groove was formed on the side wall of the piston plate, into which a universal bicycle tube (size: $12-1 / 2 \times 1.75 \times 2-1 / 4$ A/V NM) was inserted and inflated (Fig. 6(b)). A special fitting was fabricated to connect an air line to the tube so the pressure could be adjusted as required during the consolidation process. The tube, when inflated, provides a seal with the internal wall of the consolidation chamber, while overcoming the frictional resistance to move vertically downwards under the consolidation pressure applied to the upper chamber. Both the tube and consolidation pressures are controlled using individual pressure regulators coupled with pressure transducers and digital displays. Trial tests at various combination pressures were carried out and results have shown that a consolidation pressure of $150 \mathrm{kPa}$ was adequate to produce quality repeatable samples with an undrained strength, $\mathrm{c}_{\mathrm{u}}$, of $35 \mathrm{kPa}$. This strength is sufficient to evaluate the performance of granular columns as the sample provides some lateral restraint to the column while not restricting any deformation. Ensuring $75 \mathrm{kPa}$ of pressure difference between the rubber tube $(225 \mathrm{kPa})$ and loading chamber $(150 \mathrm{kPa})$ provides successful sealing with the chamber side wall and reduces the risk of consolidation pressure being lost.

Fully consolidated samples are extruded from the consolidation chamber and trimmed to size in preparation for column installation (Fig. 6(c)). Granular columns are installed into preformed holes using wet compaction of uniformly graded basalt (90\% of the material having $1-1.5 \mathrm{~mm}$ particle sizes). The holes are formed by helical augers that are mounted onto a special manufactured drilling rig. The rig consists of an electric motor that maintains a constant drill speed of $19 \mathrm{r} / \mathrm{min}$ and a rack and pinion mechanism that controls vertical movement. Previous studies (Sivakumar et al. 2002) have shown this to be a high quality, repeatable method for column installation. The uniformity of the column was monitored by measuring the density of the column along the length.

\section{Test Procedure}

This paper evaluates the complex testing system developed to perform a series of tests to examine and understand the performance of a foundation supported on granular columns. Initial results obtained confirm the accuracy and functionality of the newly developed system. A consolidated sample was placed into the triaxial system and was initially subjected to an isotropic effective consolidation pressure of $75 \mathrm{kPa}$. This was then followed by $\mathrm{K}_{\mathrm{o}}$ loading whereby the vertical and the horizontal pressures were increased slowly to $125 \mathrm{kPa}$ and $100 \mathrm{kPa}$, respectively, representing a $\mathrm{K}_{\mathrm{o}}$ value of 0.8 . This value is slightly higher than $\mathrm{K}_{\mathrm{o}}$ for normally consolidated kaolin (Navaneethan 2003; Burland 1990). Back pressure in the sample was maintained at $200 \mathrm{kPa}$ all the time. Foundation loading was applied by ramping pressure in the pneumatic controller at a rate of $0.8 \mathrm{kPa} / \mathrm{h}$. The rate of loading is sufficient to achieve a fully drained loading condition. Foundation loading typically lasts 2-3 weeks; this allows an overall foundation displacement of between $15-20 \mathrm{~mm}$. It is difficult to ascertain the termination point for each test as the loading is stress controlled. This procedure is repeated to examine samples with various conditions, three of which are presented in this paper.

\section{Results}

The research outlined as part of the program is in progress and as stated previously the purpose of this paper is only to highlight the development of the new dual-loading triaxial system for testing the performance of granular columns in relation to settlement control. 


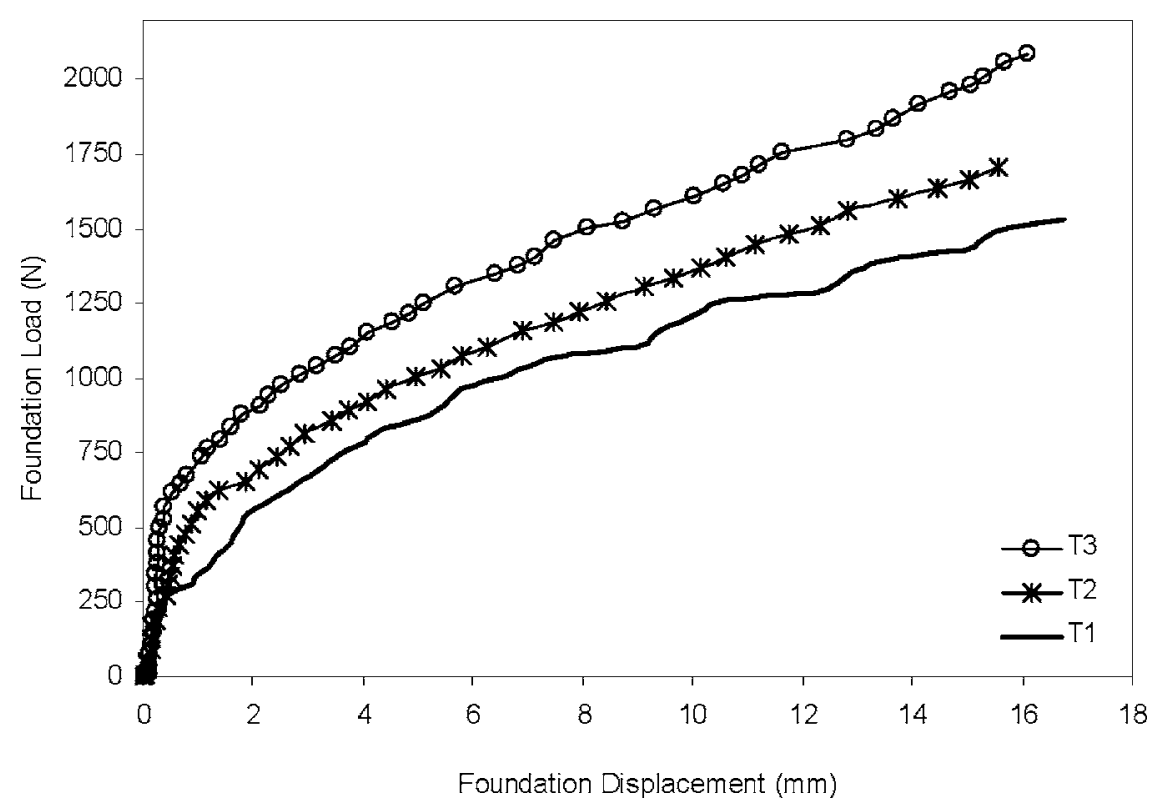

FIG. 7-Applied foundation load versus displacement.

This paper uses results obtained from three tests; T1, T2, and T3. The conditions applied in these tests were for foundation loading on-T1, unreinforced soft clay; $\mathrm{T} 2$, clay reinforced with a single 25-mm diameter column of 125-mm length, and T3, clay reinforced with a single $25-\mathrm{mm}$ diameter column $250-\mathrm{mm}$ long. The latter two tests correspond to length to diameter ratios of 6 and 10, respectively. The results to date validate the equipment and indicate that the study has the potential to alter how future model studies are conducted and provide significant developments in the understanding of the settlement performance of vibrated stone columns.

\section{Samples}

For the three samples discussed here, initial water content of the clay after consolidation was approximately $50.5 \%$ with a variation of $0.2 \%$. In each sample an attempt was made to measure the variation of water content along the sample length. The results have shown that the water content at the bottom of the sample was about $0.75 \%$ higher than at the top. This may be attributed to side friction between the consolidation chamber and the clay. The implication of this is that not all the consolidation pressures applied at the top of the sample are transferred to the bottom of the chamber. Drainage during the consolidation of the slurry in the consolidation chamber was allowed only through the bottom of the chamber. Drainage through both top and bottom boundaries can accelerate the consolidation process considerably. However, the process will inevitably generate a complicated stress variation along the sample length. For example, if consolidation is allowed from both top and bottom, the clay close to the two boundaries will consolidate quickly, and consequently, the partly or fully consolidated clay close to the top boundary will act as a buffer restricting the pressure being applied to the clay underneath.

\section{Foundation Loading}

Figure 7 shows the foundation load-displacement responses for the unreinforced and reinforced samples. The loading was stress con- trolled and applied at a rate of $0.8 \mathrm{kPa} / \mathrm{h}$ to ensure a fully drained condition. The results indicate that at a footing displacement of $s$ $=10 \mathrm{~mm}$ the load carrying capacity of the unreinforced deposit was $1.25 \mathrm{kN}$. This increased to $1.4 \mathrm{kN}$ and $1.6 \mathrm{kN}$, respectively. This represents an increase of 12 and $28 \%$ for the composite samples of $\mathrm{T} 2$ and $\mathrm{T} 3$, respectively. The $25-\mathrm{mm}$ diameter column represents an area replacement ratio $\left(\mathrm{A}_{\mathrm{s}}\right)$ of $17 \%$. In relation to the settlement consideration, the sample with no column exhibited a footing settlement of $6.5 \mathrm{~mm}$ at a foundation load of $1 \mathrm{kN}$. This settlement reduced to $4.5 \mathrm{~mm}$ and $2.2 \mathrm{~mm}$ in the case of $125-\mathrm{mm}$ long and 250-mm long columns at the same loading condition. These reduced settlements correspond to settlement reduction factors of 0.69 and 0.34 for $\mathrm{T} 2$ and $\mathrm{T} 3$, respectively.

The load-sharing mechanism of the composite clay/gravel columns was examined by analyzing the pressures measured by the pressure cells located beneath the footing. Figure 8 relates the pressure cells located under the foundation and away from it (PT1: center and directly on the granular column, PT2: underneath the footing but away from the column, and PT3: located away from the footing). The results have been shown for tests performed on the unreinforced sample (T1) and on a sample reinforced by a 125-mm (T2) and 250-mm (T3) long granular column $25 \mathrm{~mm}$ in diameter. The primary difference shown in Fig. 8 relates to the pressure transmitted onto the longer column in T3 in which the vertical pressure on the top of the column was approximately $1100 \mathrm{kPa}$ at a footing displacement of $s=10 \mathrm{~mm}$. In the same test, the pressure read by PT2 was approximately $600 \mathrm{kPa}$ which is nearly the same as that on the unreinforced sample at the same footing displacement. This corresponds to a stress ratio of $\left(\sigma_{\mathrm{vg}}^{\prime} / \sigma_{\mathrm{vc}}^{\prime}\right)$ of 1.86 . This ratio is somewhat smaller than expected; however, it should be noted that (a) the area replacement ratio adopted in this particular test is only $17 \%$, and (b) the stress ratios are usually high during undrained loading and will reduce with the clay carrying more load as the consolidation process progresses. It should be noted here that the boundary condition at the top of the sample (including the footing area) is rigid and therefore there will be pressure variation regardless of whether or not granular columns are present in the sample. 


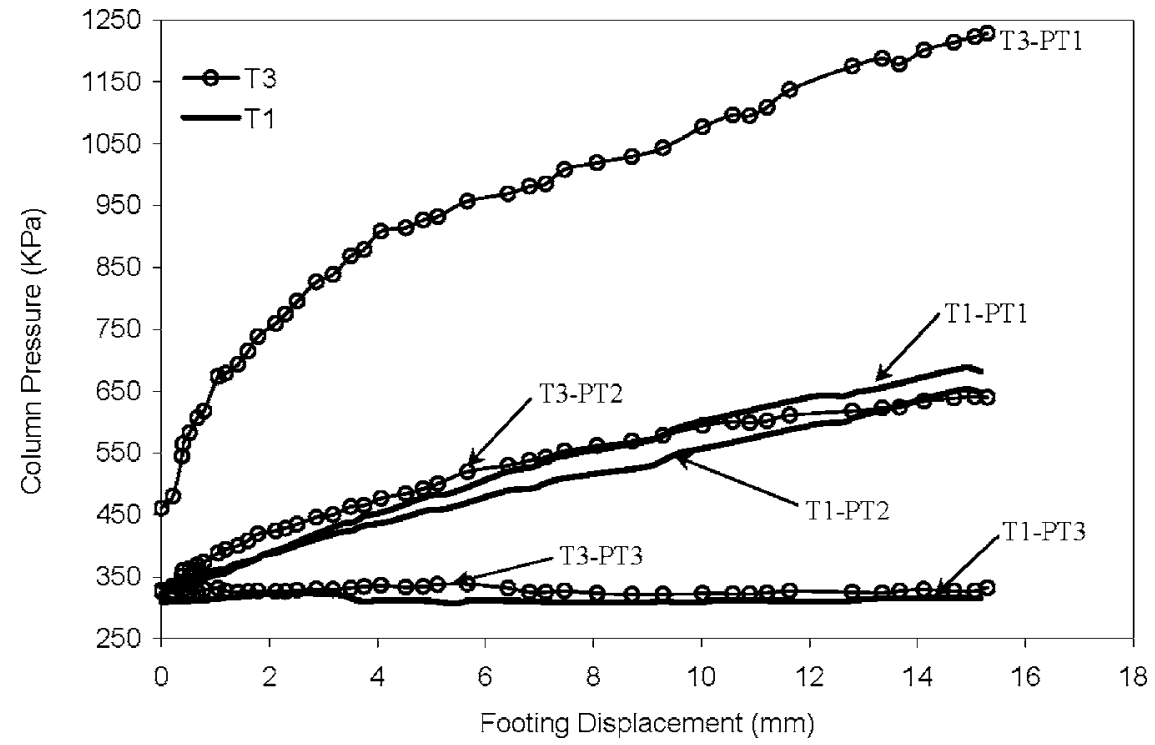

FIG. 8-Pressures read by PT1, PT2, and PT3 during foundation loading.

At the end of each test, the columns were exhumed to examine visually the deformation patterns. This revealed that the shorter column had no distinct variations in column diameter compared to the longer column, which showed significant deformations in the upper region. The shorter column of $125-\mathrm{mm}$ long remained somewhat unchanged; however, the longer $250-\mathrm{mm}$ column showed signs of overall compression. Coupling the excavated column profiles with the information presented in Figs. 7 and 8, it may be assumed that there was a reduced load transfer to the lower sections of the longer column since no deformation was observed. These results correspond to previous research conducted by (Hughes and Withers 1974) where they stated that longer columns fail by bulging and shorter columns penetrate into the underlying soft clay bed and fail in end bearing resistance.

In the present study, the circumference boundary of the sample is flexible. Research has shown that the ratio between the diameter of the sample and the footing, $\mathrm{D}_{\mathrm{s}} / \mathrm{D}_{\mathrm{f}}$, may have to be greater than five to avoid boundary effects. Some experimental evidence obtained by the lateral strain gage attached to the sample substantiates this claim. Figure 9 displays the lateral displacements recorded during the foundation loadings of T1, T2, and T3. Lateral displacement is represented by an increase or decrease in radius of the sample. Figure 9 shows the difference in lateral displacement of the unreinforced and reinforced samples when the footing was loaded to be approximately $0.075 \mathrm{~mm}$ at a footing displacement of $10 \mathrm{~mm}$. This change in diameter can be considered insignificant given the size of the sample and suggests that the $\mathrm{D}_{\mathrm{s}} / \mathrm{D}_{\mathrm{f}}$ is sufficiently large to avoid boundary effects.

Based on the above information, it may be argued that the 125-mm long column in T2 was too short; however, using the same interpretation, the $250-\mathrm{mm}$ long column in T3 may be overly conservative. It may be concluded that the optimum column length in

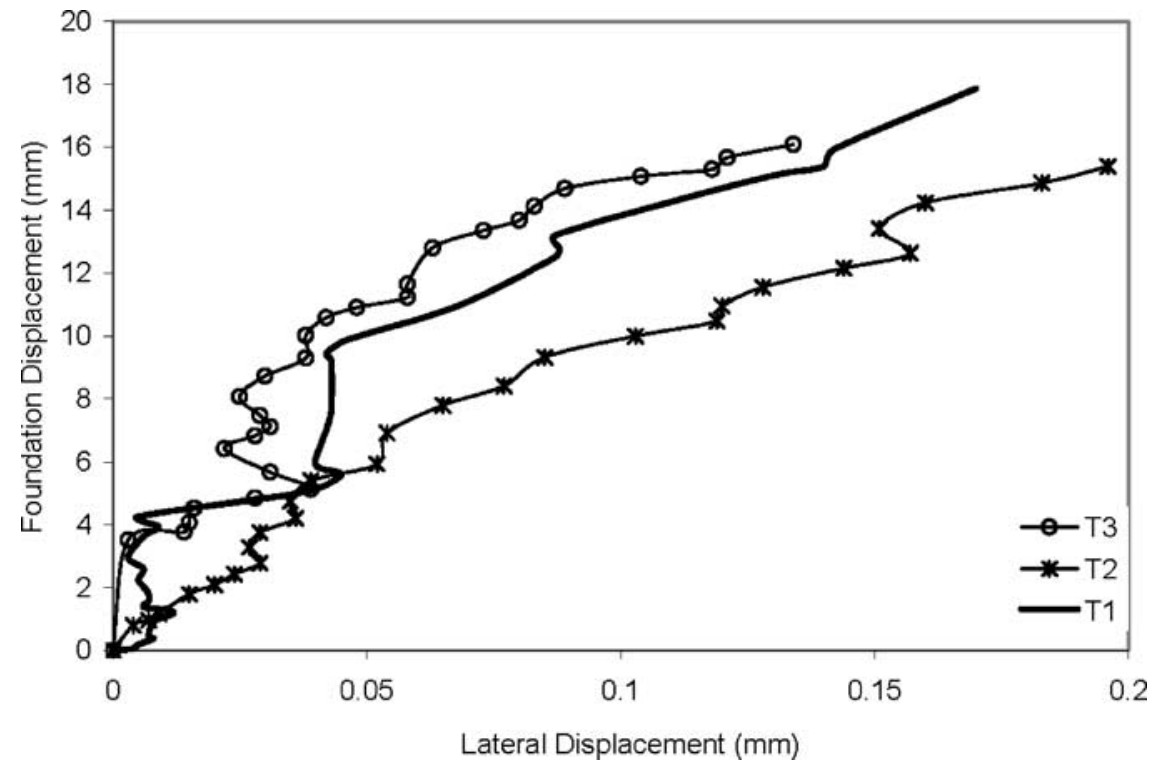

FIG. 9-Boundary effects with foundation plunge. 
this situation may be between $\mathrm{L} / \mathrm{d}$ ratios of 6 to 10 . However, future studies investigating column lengths beyond $250 \mathrm{~mm}$ will substantiate this aspect. The preliminary work agrees with studies conducted by $\mathrm{Hu}$ (1995) and McKelvey (2002) who reported similar findings for optimizing column length; however, their proposals relate to bearing capacity rather than to settlement.

In all three tests, the pressure cell located at PT3 read similar values, of the order of $315 \mathrm{kPa}$. The initial pressures appeared to rise slightly during early loading up to a footing displacement of $6 \mathrm{~mm}$; beyond this point the pressure leveled off and remained constant. This may be a consequence of surface heave due to foundation plunge. Heave is restricted as the top plate (away from the footing) represents a rigid boundary surface while also maintaining a $\mathrm{K}_{\mathrm{o}}$ load. It is reasonable to assume that some additional stress concentration will form around the immediate proximity of the plunging foundation; however, this reduces exponentially with increased distance from the center.

The experimental results presented serve to validate the functioning of the newly developed triaxial setup and the innovative approach to produce large diameter samples. Further analysis of the results is beyond the scope of this paper. As the study is ongoing recommendations cannot be declared until additional tests relating to various $\mathrm{L} / \mathrm{d}$ ratios, area ratios, single and multiple column conditions are performed. The development of such tests would improve numerical modeling of stone columns and provide increased confidence in their design.

\section{Concluding Remarks}

This paper discusses an innovative design of a large triaxial test setup and one-dimensional consolidation chamber developed to examine the settlement characteristics of a foundation supported on soft clays reinforced with a single or a group of stone columns. Tests are conducted on large samples of $300-\mathrm{mm}$ diameter by 400-mm high under drained conditions. Preliminary results validate the accuracy and functionality of the system. This equipment produces high quality test data that will lead to an improved testing protocol for future studies on ground improvement. A limitation of the test system is that the top plate on the sample represents a rigid boundary condition. Modifications for future studies may incorporate a flexible boundary condition. This would enhance the versatility of the system and allow the effect of differential settlement and surface heave to be evaluated.

\section{Acknowledgments}

The authors would like to thank Keller Ground Engineering, UK, for funding for the project, Department of Education and Learning (DEL), Northern Ireland, and The Institution of Engineers Ireland (IEI), who provided a research scholarship to Mr. J. Black. VJ Tech Ltd. manufactured the triaxial test setup. Mr. T. Crothers and his team in the Mechanical Workshop at Queen's University, Belfast, fabricated the consolidation chamber.

Anderson, W. F., Pyrah, I. C., and Fryer, S., 1991, "A Clay Calibration Chamber for Testing Field Devices," Geotech. Test. J., Vol. 14, No. 4, pp. 440-450.

Balaam, N. P., 1978, "Load Settlement Behaviour of Granular Piles," Ph.D. Thesis, University of Sydney, Australia.

Black, J. A., 2003, "Influence of Preparation Techniques on the Index Properties of Clay," B.Eng. dissertation project, Department of Civil Engineering, Queen's University, Belfast.

Burland, J. B., 1990, "On the Compressibility and Shear Strength of Natural Clays," Geotechnique, Vol. 40, No. 3, pp. 329-378.

Hughes, J. M. O. and Withers, N. J., 1974, "Reinforcing of Soft Cohesive Soils with Stone Columns," Ground Eng., Foundation Publications Limited, May, pp. 42-49.

Hu, W., 1995, "Physical Modeling of Group Behaviour of Stone Column Foundations," Ph.D. Thesis, University of Glasgow.

McKelvey, D., 2002, "Performance of Vibro Stone Column Foundations in Deep Soft Ground," Ph.D. Thesis, Queen's University, Belfast.

McKelvey, D., Sivakumar, V., Bell, A., and Graham, J., 2004, “A Laboratory Model Study of the Performance of Vibrated Stone Columns in Soft Clay," J. Geotech. Eng., Vol. 152, pp. 1-13.

Muir Wood, D., Hu, W., and Nash, D. F. T., 2000, "Group Effect in Stone Column Foundations: Model Tests," Geotechnique, Vol. 50, No. 6, pp. 689-698.

Navaneethan, T., 2003, "Pre-yield Characteristics and Earth Pressure Coefficient of Over Consolidated Clays," Ph.D. Thesis, Queen's University, Belfast.

Serridge, C. J., 2004, "The Use of Reclaimed/Recycled Material in Vibro Stone Column Ground Improvement Techniques," Proceedings 5th International Conference on Ground Improvement Techniques, pp. 273-280.

Sivakumar, V., Doran, I. G., and Graham, J., 2002, "Particle Orientation and its Influence on the Mechanical Behaviour of Isotropically Consolidated Reconstituted Clay," Engineering Geology, Vol. 66, pp. 197-209. 